\title{
The Timing of Contests
}

\author{
Gilles Grandjean* and Petros G. Sekeris ${ }^{\dagger}$
}

\begin{abstract}
We develop a simple model to analyze the timing of contests. When the odds of winning a contest are exogenously given, we show that if either the players discount the future or if the total cost of contest is smaller in the future, there exist subgame perfect equilibria where both players settle, anticipating a contest in the future. With endogenous efforts, the aggregate efforts expanded in a contest are smaller if the contest occurs in the future when the relative effort productivities remain constant or diverge over time, thus creating scope for delay in contests. When the effort productivities converge over time, the total efforts may be greater under a future contest. As a consequence players either settle over the two periods, or else they initiate a contest immediately.
\end{abstract}

Keywords: Delay, Contest, Dynamic Game, War

JEL classification: C72; D7

*Belgian National Research Fund (FNRS) post-doctoral researcher at Facultés Universitaires Saint-Louis, Brussels, Belgium. Address: CEnter for Research in EConomics, 38, boulevard du Jardin Botanique, B-1000 Bruxelles, Belgium. Tel: +32 221179 39. e-mail: grandjean@fusl.ac.be.

${ }^{\dagger}$ Petros Sekeris (corresponding author) is Principal Lecturer at the University of Portsmouth. Richmond Building, Portland Road, PO13DE Portsmouth, United Kingdom. Tel: +44 2392844244 . Contact e-mail: petros.sekeris@port.ac.uk 


\section{Introduction}

When property rights over a resource fail to be perfectly defined and enforced, agents may devote efforts to claim ownership over the resource and confront each other in a contest. Examples of such situations include legal disputes, political campaigning for securing voters' support, commercial expansion for the control of market shares, or violent conflict over the control of wealth and territory.

In this paper, we develop a simple model to analyze the timing of contest. The model features 2 players owning a share of a contestable resource that produces some consumption units in each of the game's 2 periods. The players may choose to contest the status quo allocation in any period. If a contest occurs, each player wins it with some probability, and the winner gets the control over the entire resource for the remaining periods. Both players are risk neutral, and know from the beginning the relative strength of each party in the current and in the future period. We first consider a model where the odds of winning a contest in a given period as well as the cost of the contest are exogenously given. We then develop a model where the players choose the costly effort they put in a contest, which together with the exogenous effort productivity parameters determine the odds of winning the contest through a standard contest success function.

Two applications fit well our framework: litigation and armed conflict. Consider first a party deciding whether or not to suit another party over the allocation of physical or intellectual property rights. A single party may fill a suit, and once a trial is initiated, both parties exert efforts to tilt the jury in their favor. ${ }^{1}$ After a court implemented a decision, the case is closed, thus effectively implying that contests cannot recur. A second application of our model can be found

\footnotetext{
${ }^{1}$ The theory of contest has extensively been applied to model the outcome of trials (see Katz 1988, Farmer and Pecorino 1999, Bernardo et al. 2000, Gong and McAfee 2000, Hirshleifer and Osborne 2001, Robson and Skaperdas 2008).
} 
in military contests. Consider again two parties vying for the control of some short-lived resource, where instead of resolving the dispute in front of a tribunal, contestants confront each other on the battleground. Parties therefore ought to decide whether and when to attempt obtaining the resources' ownership through violent means, given that the relative strength of the parties may change as time passes. Our contribution helps understanding whether and when a contest occurs, given the initial allocation of the resources among the contestants, and given the evolution of their relative strength. This contribution is therefore of particular relevance for better understanding the debate among political scientists over whether countries are more likely to engage in armed conflict under Balance of Power (Morgenthau 1960) or under Power Transition (Organski 1958, Organski and Kugler 1980). As will become clear our results accommodate both theories, depending on the models' parameters, hence demonstrating with a simple model the need to further elaborate existing theories of international relations.

When the odds of winning a contest are exogenously given, we show that at the subgame perfect equilibrium a contest either occurs today or never occurs if the players do not discount future payoffs and the cost of the contest remains constant over time. If the players discount the future or if the total cost of the contest is smaller in the future, then there are subgame perfect equilibria where both players settle, anticipating a contest in the future. Indeed, suppose the cost of a contest remains constant over the two periods, the players do not discount the future payoffs, and a contest is expected to occur at a future date. Then, each player knows that he will have to bear the cost of a contest, whatever his choice in the current period, and is indifferent between bearing that cost today or at a future date. It then follows that if one of the two players prefers a contest at a future date over an immediate one, it must be that the other prefers an immediate contest over a future one. This stops being true when the players discount the future or when the costs of a contest are 
expected to be lower in the future, as the players cease being indifferent between bearing the cost of the contest today or at a future date.

With endogenous efforts, the cost of the contest equals the effort spent by the players. For constant relative effort productivities, the effort invested in a contest is greater in the initial period than in the future since the winner of the contest enjoys the resource for the remaining periods. We name this mechanism the wealth effect. However, if the effort productivities converge over time, the sum of efforts may be greater under a future contest, since the closer the parties' fitness, the higher their investment when the contest technology is modelled through a contest success function. These effects, combined with the discounting effect mentioned above determine whether and when a contest occurs.

The incentives of players to initiate a contest may be greater in dynamic games than in their static counterparts. In a model where the players first choose their costly effort and then decide whether to settle, Skaperdas (2006) and McBride and Skaperdas (2007) show that the cost of future settlements may encourage players to initiate an immediate contest. Garfinkel and Skaperdas (2000) and Powell (2012) show that when present victories translate into a future strategic advantage players are further induced to initiate a contest in the short run. In other setups, the prospects of the future disincentivizes players to enter in a contest. Garfinkel (1990) shows in an infinitely repeated game that settlements may be sustained with trigger strategies where contest initiators are punished by reversion to permanent contest equilibria. Bester and Konrad (2005) show in a repeated game where in each period the resource is randomly allocated to the players that they have incentives to defer the contest to a period in which the allocation is very unequal so that the cost of the contest is low as the resource constraint becomes binding for one player. Konrad (2012) points at the "discouragement effect": the expected future interaction between contestants is 
likely to reduce the present discounted benefits from competing in a contest, therefore incentivizing players to contain or even totally forgo investments in the contest. ${ }^{2}$

Bester and Konrad (2004) provide a rationale for short run settlement in a dynamic framework where the likelihood of success in a contest is exogenous and shifting over time, and there is an advantage of defense. For example, it may indeed be the case that the stronger agent prefers to delay the contest as he expects to become even stronger, while the weakest agent does not initiate a contest to benefit from the defensive advantage at a future period. By endogenizing the contest effort of the players, we derive similar results without requiring a defensive advantage.

The rest of the paper is organized as follows. In the next section we present the model when the contest effort is exogenous, Sections 3 solves the game for endogenous efforts, Section 4 proposes a brief application to International Relations, and the last section concludes.

\section{The model with exogenous effort}

A given resource generates $W$ consumption units in each of 2 periods. Two players, $i$ and $j$, initially have a claim over a share of the resources. We denote by $\alpha_{k}$ the fraction of the resources owned by player $k$. The two players live two periods, and decide in each period whether they accept the status quo allocation of the resources, or whether they initiate a contest to attempt modifying it. If both players accept the status quo in a period, each player consumes his share of the units produced in that period, and the game moves on to the next period. Otherwise, a contest occurs, and the player who wins it obtains the total resources for the remaining periods. The players discount their second period payoff according to their discount factor $\delta_{k}$, they have full information about the game, and are risk-neutral. In addition, the allocations are assumed to be indivisible, so that a

\footnotetext{
${ }^{2}$ For an overview of dynamic contests, see Konrad (2009).
} 
player cannot transfer part of his allocation to the other player to avoid a contest.

In this section the probability with which player $k$ wins the resources if a contest occurs in period $t$ is exogenously given, and we denote it by $p_{k, t}$. If a contest occurs in period $t$, either player $i$ or player $j$ wins it, that is $p_{i, t}+p_{j, t}=1$. In addition, to capture the inefficiencies that typically arise in contests, we assume that the contest involves an exogenous cost $F_{k, t}$ to player $k .^{3}$ We sometimes write $\alpha$ for $\left(\alpha_{i}, \alpha_{j}\right), p_{t}$ for $\left(p_{i, t}, p_{j, t}\right)$, and $F_{t}$ for $\left(F_{t, i}, F_{t, j}\right)$. In each period, both players simultaneously choose whether they accept the status quo allocation or whether they contest it. If a player does not accept the status quo allocation in a period, a contest occurs and each player obtains the resources for the remaining periods with some probability. Otherwise, if no player has contested the status quo in a previous period, and both players accept the status quo in the current period, each player gets his allocation. As a tie-breaking rule, we assume that in case of indifference the players prefer accepting the settlement. Formally, the strategy of player $k$ in period $t$ is $\sigma_{k, t} \in\{a, c\}$, where $a$ stands for "accept" the status quo, while $c$ stands for "contest". We let $\sigma_{k}=\left(\sigma_{k, 1}, \sigma_{k, 2}\right)$ be the strategy of player $k$, and $\sigma$ be the strategy profile $\left(\sigma_{i}, \sigma_{j}\right)$. Abusing notation, we also refer to the strategy profile of the players in period $t$ as $\sigma_{t}=\left(\sigma_{i, t}, \sigma_{j, t}\right)$. The utility of player $k$ is given as follows.

\footnotetext{
${ }^{3}$ Contests involve rent-dissipation since otherwise productive resources are devoted to improving one's winning odds (Tullock 1980). Moreover the value of the resources can be reduced because of the destructiveness of a contest (Grossman and Kim 1995, De Luca and Sekeris 2012), or as a consequence of the players' risk aversion (Skaperdas 1991, and Skaperdas and Gan 1995).
} 


$$
\left\{\begin{array}{l}
U_{k}(\sigma)=\alpha_{k} W\left(1+\delta_{k}\right), \text { if } \sigma_{1}=\sigma_{2}=(a, a) \\
U_{k}(\sigma)=\alpha_{k} W+\delta_{k}\left(p_{k, 2} W-F_{k, 2}\right), \text { if } \sigma_{1}=(a, a), \text { and } \sigma_{l, 2}=c \text { for some } k=i, j \\
U_{k}(\sigma)=\left(1+\delta_{k}\right) p_{k, 1} W-F_{k, 1}, \text { if } \sigma_{l, 1}=c \text { for some } k=i, j
\end{array}\right.
$$

By backward induction, we characterize the subgame perfect equilibrium $\left(\sigma^{*}\right)$ of the model.

Proposition 1. The subgame perfect equilibria $\sigma^{*}$ of the model are given by:

(i) $\sigma_{k, 2}^{*}=c$ for $k=i, j$ if $p_{k, 2} W-F_{k, 2}>\alpha_{k} W$; otherwise, $\sigma_{k, 2}^{*}=a$.

(ii) Suppose $\sigma_{2}^{*}=(a, a)$. Then $\sigma_{k, 1}^{*}=n$ if $\left(1+\delta_{k}\right) p_{k, 1} W-F_{k, 1}>\alpha_{k} W\left(1+\delta_{k}\right)$; otherwise, $\sigma_{k, 1}^{*}=y$.

(iii) Suppose $\sigma_{2}^{*} \neq(a, a)$. Then $\sigma_{k, 1}^{*}=n$ if $\left(1+\delta_{k}\right) p_{k, 1} W-F_{k, 1}>\alpha_{k} W+\delta_{k}\left(p_{k, 2} W-F_{k, 2}\right)$; otherwise, $\sigma_{k, 1}^{*}=y$.

Case (i) determines second period equilibrium behavior, while cases (ii) and (iii) pin down first period equilibrium behavior when a settlement or a contest is expected in period 2 .

These results are obtained simply by comparing the utility of the players under the different scenarii. If a settlement is expected to occur in period 2, the two players settle in period 1 if both are better-off by enjoying their allocation during the two periods than under a contest in period 1 . On the other hand, if a contest is expected to occur in period 2, a player settles in period 1 if he is better-off by delaying the contest than by precipitating it.

A necessary condition for a contest to occur in period 2 at equilibrium is that the sum of utilities in a delayed contest be higher than in an immediate contest. Formally the following condition should be satisfied:

$$
W\left(1+\delta_{i} p_{i, 2}+\delta_{j} p_{j, 2}\right)-\delta_{i} F_{i, 2}-\delta_{j} F_{j, 2}>W\left(1+\delta_{i} p_{i, 1}+\delta_{j} p_{j, 1}\right)-F_{i, 1}-F_{j, 1}
$$


Proposition 2 states that when the sum of utilities is higher in a future contest than in an immediate one while a contest is expected to occur at a future date, the players settle in the current period for some relative strengths provided some mild conditions on the evolution of the cost of a contest are satisfied.

Proposition 2. For all $\alpha, p_{2}$ and $F_{2}$ such that $\sigma_{2}^{*} \neq(a, a)$, there exists $p_{1} \in[0,1]^{2}$ such that $\sigma_{1}^{*}=(a, a)$ if Condition (1) holds and $\alpha_{k} W+\delta_{k}\left(p_{k, 2} W-F_{k, 2}\right) \geq-F_{k, 1}$, for $k=i, j$.

Proof. Let Condition (1) be satisfied and let $\alpha_{k} W+\delta_{k}\left(p_{k, 2} W-F_{k, 2}\right) \geq-F_{k, 1}$, for $k=i, j$, . Without loss of generality, suppose that $\left(p_{i, 2}-\alpha_{i}\right) W>F_{i, 2}$ so that $\sigma_{i, 2}^{*}=c$. We then have $\sigma_{1}^{*}=(a, a)$ if the following two conditions are satisfied:

$$
\begin{aligned}
& \alpha_{i} W+\delta_{i}\left(p_{i, 2} W-F_{i, 2}\right) \geq\left(1+\delta_{i}\right) p_{i, 1} W-F_{i, 1} \\
& \left(1-\alpha_{i}\right) W+\delta_{j}\left(\left(1-p_{i, 2}\right) W-F_{j, 2}\right) \geq\left(1-p_{i, 1}\right)\left(1+\delta_{j}\right) W-F_{j, 1}
\end{aligned}
$$

Let $\bar{p}_{i, 1}$ be the value of $p_{i, 1}$ such that $(\mathrm{A})$ holds with equality. We have $\bar{p}_{i, 1}>0$. Indeed, for $p_{i, 1}=0$, (A) holds strictly since $\sigma_{i, 2}^{*}=c$ implies that the left-hand side is positive, while the right hand side is negative $\left(-F_{i, 1}\right)$. Suppose that $\bar{p}_{i, 1} \leq 1$. Then, from Condition (1), (B) holds with strict inequality for $p_{i, 1}=\bar{p}_{i, 1}$, while (A) holds by definition of $\bar{p}_{i, 1}$. If on the other hand $\bar{p}_{i, 1}>1$, then $(\mathrm{A})$ holds with strict inequality for $p_{i, 1}=1$, while (B) holds by assumption since $\alpha_{j} W+\delta_{j}\left(p_{j, 2} W-F_{j, 2}\right) \geq-F_{j, 1}$.

Consider as a benchmark a situation where the players do not discount the future $\left(\delta_{i}=\delta_{j}=1\right)$, and the cost of a contest is constant over time $\left(F_{k, 1}=F_{k, 2}=F_{k}, k \in\{i, j\}\right)$. The left-hand side and the right-hand side of Condition 1 are then equal, so that if a contest is expected to occur in period 2 and say player $i$ prefers to settle in period 1 , then player $j$ necessarily prefers to initiate a 
contest in period 1 , and there is thus no scope for delay. If on the other hand the aggregate utility under a contest in period 2 is higher than under a contest in period 1, Proposition 2 establishes that players settle in period 1 for some current relative strengths if a player never has incentives to precipitate a contest that is lost for sure, a condition that is always satisfied when the contest costs incurred by each player do not increase over time.

Bester and Konrad (2004) develop a model of contest between 2 players, where the likelihood of a success in a contest is higher when the contest is initiated by the other player. ${ }^{4}$ Letting the probability of success depend on the identity of the player initiating the contest, we note by $p_{k, t}(l)$ the probability that $k$ wins the contest in period $t$ if $l$ initiates it. Then, a defensive advantage is assumed if $p_{k, t}(-k)>p_{k, t}(k)$, and it implies that the sum of probabilities of success from initiators of a conflict is smaller than $1\left(p_{i, t}(i)+p_{j, t}(j)<1\right)$. Assuming unit discount factors $\left(\delta_{i}=\delta_{j}=1\right)$ and that a contest is expected to be initiated by player $i$ in period 2, player $i$ settle in period 1 if $\alpha_{i} W+p_{i, 2}(i) W-F_{i, 2}>2 p_{i, 1}(i) W-F_{i, 1}$ while player $j$ settles in period 1 if $\alpha_{j} W+p_{j, 2}(i) W-F_{i, 2}>2 p_{j, 1}(j) W-F_{j, 1}$. It follows that Condition 1 then becomes

$$
2 W\left(1-p_{i, 1}(i)-p_{j, 1}(j)\right)>F_{i, 2}+F_{j, 2}-F_{i, 1}-F_{j, 1},
$$

and this condition is always satisfied if the contest costs remain constant over the two periods. When a defensive advantage is assumed, discounting or decreasing contest costs is not required for delay to occur at equilibrium.

\footnotetext{
${ }^{4}$ Their focus is on armed conflicts. They argue that there are cases where the armies are more efficient in defense.
} 


\section{The model with endogenous effort}

We develop in this section a model where the likelihood of a success in a contest is determined by the effort exerted by the players in order to win the resources. In a given period $t$, each player announces simultaneously in a first stage whether he accept the status quo allocation of the resources, or whether he initiates a contest to attempt modifying it. If both players accept the status quo in a period, each player consumes his share of the units produced in that period, and the game moves on to the next period. Otherwise, a contest occurs, and each player obtains the resources for the remaining periods with some probability, determined by the effort the players exert in a second stage. ${ }^{5}$ Players invest efforts in improving their odds of winning a potential contest at a constant marginal cost. ${ }^{6}$ The contest technology is given by a standard contest success function so that if the players respectively exert efforts $e_{k, t}$ and $e_{-k, t}$, the probability that player $k$ eventually obtains the total control of the resources if a contest is initiated in the first stage of period $t$ is given by $p_{k}\left(e_{k, t}, e_{-k, t}\right)=\frac{\theta_{k, t} e_{k, t}}{\theta_{k, t} e_{k, t}+\theta_{-k, t} e_{-k, t}}$, where $\theta_{k, t}$ stands for the productivity of player $k$ 's effort in a contest in period $t$. The evolution of the productivity parameter from period 1 to period 2 is

\footnotetext{
${ }^{5}$ The chosen timing whereby players first decide whether or not to enter a contest and then decide the effort level is tantamount to assuming a strong commitment capacity on behalf of the players since we rule out the possibility of reneging on the first stage decision. From a conceptual viewpoint, this commitment capacity may equally be interpreted as players facing important reputation costs of violating their first stage decision, or the players' effort slowly translating in contest capacity so that the opponent is never subject to a sneak attack. From a practical viewpoint, contests such as legal or sports contests whereby the players ought to publicly declare their participation before the contest actually taking place satisfy the model's timing assumptions. Our setting equally applies to military confrontations since they necessitate military preparation which is likely to be observed -at least to some degree - by one's opponent.

${ }^{6}$ We assume away budget constraints that would burden the analysis without bringing any additional insight. The cost of effort can be interpreted in various ways including foregone production given some linear production function, or a constant marginal utility of leisure time.
} 
exogenously given. We assume that the players are able to enforce a settlement when it is the outcome of the first stage.

The strategy of each player consists, in each period, of a choice to accept or contest the status quo in a first stage, and of a level of effort in the second stage, for each action profile chosen in the first stage. Formally, in the first stage of period $t$ player $k$ chooses $\sigma_{k, t} \in\{a, c\}$ and we let $S$ be the state in the second stage of period $t$ when $\sigma_{t}=(a, a)$, while $C$ is the state in the second stage when $\sigma_{t, l}=c$ for some $l=i, j$. The strategy of player $k$ in period $t$ is $\gamma_{k, t}=\left(\sigma_{k, t}, e_{k, t}(S), e_{k, t}(C)\right)$, where $\sigma_{k, t} \in\{a, c\}$, and $e_{k, t}(S), e_{k, t}(C) \in \mathcal{R}^{+}$. We let the strategy of player $k$ be $\gamma_{k}=\left(\gamma_{k, 1}, \gamma_{k, 2}\right)$, and $\gamma$ is the strategy profile $\left(\gamma_{i}, \gamma_{j}\right)$.

Assuming that the players have the same discount factor $\delta$, the utility of player $k$ is given as follows.

$$
\begin{aligned}
U_{k}(\gamma) & =(1+\delta) \alpha_{k} W-e_{k, 1}(S)-\delta e_{k, 2}(S), \text { if } \sigma_{1}=\sigma_{2}=(a, a) \\
U_{k}(\gamma) & =\alpha_{k} W-e_{k, 1}(S)+\delta\left(\frac{\theta_{k, 2} e_{k, 2}(C)}{\theta_{k, 2} e_{k, 2}(C)+\theta_{-k, 2} e_{-k, 2}(C)} W-e_{k, 2}(C)\right) \\
\text { if } \sigma_{1} & =(a, a), \text { and } \sigma_{2} \neq(a, a) \\
U_{k}(\gamma) & =(1+\delta) \frac{\theta_{k, 1} e_{k, 1}(C)}{\theta_{k, 1} e_{k, 1}(C)+\theta_{-k, 1} e_{-k, 1}(C)} W-e_{k, 1}(C) \text { if } \sigma_{1} \neq(a, a)
\end{aligned}
$$

We analyze the subgame perfect equilibrium of the game, proceeding by backwards induction. We let $e_{k, t}^{*}(S)$ and $e_{k, t}^{*}(C)$ be the equilibrium levels of effort, given the outcome of the first stage in period $t$. When both players settle in the first stage of a given period, they have no incentives to invest in appropriative activities in the second stage of that period. We thus have $e_{k, t}^{*}(S)=0$ for $k=i, j$ and $t=1,2$. If a contest is triggered in period 2 , both players choose their effort level $e_{k, 2}$ in order to maximize the following expression: 


$$
\frac{\theta_{k, 2} e_{k, 2}(C)}{\theta_{k, 2} e_{k, 2}(C)+\theta_{-k, 2} e_{-k, 2}(C)} W-e_{k, 2}(C)
$$

Combining the players' reaction functions, the equilibrium amount of effort of both players is:

$$
e_{i, 2}^{*}(C)=e_{j, 2}^{*}(C)=e_{2}^{*}(C)=\frac{\theta_{i, 2} \theta_{j, 2}}{\left(\theta_{i, 2}+\theta_{j, 2}\right)^{2}} W
$$

If a contest occurs in period 1 , player $k$ chooses the level of effort $e_{k, 1}$ that maximizes equation (4). Combining the players' reaction functions, the equilibrium amount of effort of both players is:

$$
e_{i, 1}^{*}=e_{j, 1}^{*}=e_{1}^{*}=(1+\delta) \frac{\theta_{i, 1} \theta_{j, 1}}{\left(\theta_{i, 1}+\theta_{j, 1}\right)^{2}} W
$$

Notice that player $k$ wins the contest in period $t$ when both players exert the equilibrium choices of effort with probability $p_{k, t}^{*}=\theta_{k, t} /\left(\theta_{k, t}+\theta_{-k, t}\right)$.

Denote by $\gamma^{S, C}$ a strategy profile such that $\sigma_{1}=(a, a), \sigma_{2} \neq(a, a), e_{i, 1}=e_{j, 1}=e_{1}^{*}(S)$ and $e_{i, 2}=e_{j, 2}=e_{2}^{*}(C)$. The payoff of player $k$ under settlement in period 1 and contest in period 2 , given equilibrium efforts in both periods is:

$$
U_{k}\left(\gamma^{S, C}\right)=\alpha_{k} W+\delta \frac{\theta_{k, 2}^{2}}{\left(\theta_{k, 2}+\theta_{-k, 2}\right)^{2}} W
$$

Using the same notation, we write $\gamma^{S, S}$ for the strategy profile where both choose to settle in

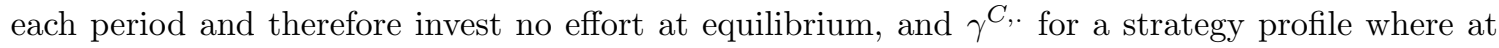
least one player initiates a contest in period 1 and both choose the equilibrium level of effort $e_{i, 1}=$ $e_{j, 1}=e_{1}^{*}(C)$. We thus have $U_{k}\left(\gamma^{S, S}\right)=(1+\delta) \alpha_{k} W$, and $U_{k}\left(\gamma^{C, .}\right)=(1+\delta) W \theta_{k, 1}^{2} /\left(\theta_{k, 1}+\theta_{-k, 1}\right)^{2}$. Comparing $U_{k}\left(\gamma^{S, C}\right)$ with $U_{k}\left(\gamma^{S, S}\right)$, settlement prevails in period 2 at equilibrium if:

$$
\alpha_{k} \geq \frac{\theta_{k, 2}^{2}}{\left(\theta_{k, 2}+\theta_{-k, 2}\right)^{2}} \quad k=i, j .
$$


Otherwise a contest occurs in period 2.

The players' decision in the first stage of period 1 depends on the expected outcome in period 2 . If a settlement is expected to occur in period 2, the two players prefer to settle in period 1 if both are better-off under a durable settlement than under an immediate contest, i.e. if $U_{k}\left(\gamma^{S, S}\right) \geq U_{k}\left(\gamma^{C, .}\right)$ for $k=i, j$. On the other hand, if a contest is expected to occur in period 2, player $k$ proposes to settle in period 1 if he is better-off under a delayed contest than under an immediate one, i.e if $U_{k}\left(\gamma^{S, C}\right)>U_{k}\left(\gamma^{C, \cdot}\right)$

The next proposition characterizes the subgame perfect equilibria of the game.

Proposition 1.bis. The subgame perfect equilibria of the model with endogenous effort are characterized by the following expressions

(i.a) $e_{i, t}^{*}(S)=e_{j, t}^{*}(S)=0$

(i.b) $e_{i, 1}^{*}(C)=e_{j, 1}^{*}(C)=e_{1}^{*}(C)=(1+\delta) \frac{\theta_{i, 1} \theta_{j, 1}}{\left(\theta_{i, 1}+\theta_{j, 1}\right)^{2}} W$

(i.c) $e_{i, 2}^{*}(C)=e_{j, 2}^{*}(C)=e_{2}^{*}(C)=\frac{\theta_{i, 2} \theta_{j, 2}}{\left(\theta_{i, 2}+\theta_{j, 2}\right)^{2}} W$

(ii.a) For $k=i, j, \sigma_{k, 2}^{*}=a$ if $U_{k}\left(\gamma^{S, S}\right) \geq U_{k}\left(\gamma^{S, C}\right)$, while $\sigma_{k, 2}^{*}=c$ otherwise.

(ii.b) If $\sigma_{2}^{*}=(a, a)$, then $\sigma_{k, 1}^{*}=a$ if $U_{k}\left(\gamma^{S, S}\right) \geq U_{k}\left(\gamma^{C, \cdot}\right)$, while $\sigma_{k, 1}^{*}=c$ if $U_{k}\left(\gamma^{S, S}\right)<U_{k}\left(\gamma^{C, .}\right)$ for $k=i, j$.

(ii.c) If $\sigma_{2}^{*} \neq(a, a)$, then $\sigma_{k, 1}^{*}=a$ if $U_{k}\left(\gamma^{S, C}\right) \geq U_{k}\left(\gamma^{C, \cdot}\right)$, while $\sigma_{k, 1}^{*}=c$ if $U_{k}\left(\gamma^{S, C}\right)<U_{k}\left(\gamma^{C, .}\right)$ for $k=i, j$.

The proof of this proposition follows directly from the equilibrium values of effort conditional on the outcome of the first stage that we have previously computed.

Analogously to the previous section, a necessary condition for a contest to occur in period 2 is that the sum of discounted payoff is higher under a contest in period 2 than under a contest in period 1, which is equivalent to requiring that the sum of discounted efforts be higher under a 
contest in period 1 than under a contest in period 2. Since the contest efforts are identical for each player, a necessary condition for delay to occur is that the effort of a player in a contest in period 1 should be higher than the present value of the effort he would exert in a contest in period 2:

$$
(1+\delta) \frac{\theta_{i, 1} \theta_{j, 1}}{\left(\theta_{i, 1}+\theta_{j, 1}\right)^{2}}>\delta \frac{\theta_{i, 2} \theta_{j, 2}}{\left(\theta_{i, 2}+\theta_{j, 2}\right)^{2}}
$$

Proposition 2.bis. states that when the sum of utilities is higher in a future contest than in an immediate one while a contest is expected to occur at a future date, the players settle in the current period for some relative strengths.

Proposition 2.bis. For all $\alpha$, and $\theta_{i, 2} / \theta_{j, 2}$ such that $\sigma_{2}^{*} \neq(a, a)$, there exists $\theta_{i, 1} / \theta_{j, 1}$ such that $\sigma_{1}^{*}=(a, a)$ if Condition (5) holds.

Proof. Let Condition (5) be satisfied. Without loss of generality, suppose that $\frac{\theta_{i, 2}^{2}}{\left(\theta_{i, 2}+\theta_{j, 2}\right)^{2}}>\alpha_{i}$ so that $\sigma_{i, 2}^{*}=c$. We then have $\sigma_{1}^{*}=(a, a)$ if both

$$
\begin{array}{r}
\alpha_{i} W+\delta \frac{1}{\left(1+\frac{\theta_{j, 2}}{\theta_{i, 2}}\right)^{2}} W \geq(1+\delta) \frac{1}{\left(1+\frac{\theta_{j, 1}}{\theta_{i, 1}}\right)^{2}} W, \\
\left(1-\alpha_{i}\right) W+\delta \frac{1}{\left(1+\frac{\theta_{i, 2}}{\theta_{j, 2}}\right)^{2}} W \geq(1+\delta) \frac{1}{\left(1+\frac{\theta_{i, 1}}{\theta_{j, 1}}\right)^{2}} W
\end{array}
$$

Let $\left(\bar{\theta}_{i, 1} / \bar{\theta}_{j, 1}\right)$ be the value of $\theta_{i, 1} / \theta_{j, 1}$ such that (A') holds with equality. We have $0<\bar{\theta}_{i, 1} / \bar{\theta}_{j, 1}<$ $\infty$. Indeed, for $\theta_{i, 1} / \theta_{j, 1}=0,\left(\mathrm{~A}^{\prime}\right)$ holds strictly since $\sigma_{i, 2}^{*}=c$ implies that the left-hand side is positive, while the right hand side is equal to zero. On the other hand, as $\theta_{i, 1} / \theta_{j, 1} \rightarrow \infty$, the right hand side of $\left(\mathrm{A}^{\prime}\right)$ converges to $(1+\delta) W$, which is the upper bound of the left-hand side. Then, from Condition (5), (B') holds with strict inequality for $\theta_{i, 1} / \theta_{j, 1}=\bar{\theta}_{i, 1} / \bar{\theta}_{j, 1}$, while (A') holds with equality by definition. 
Two forces matter to determine whether the aggregate effort spent is higher in an immediate or in a future contest. First, keeping the productivity parameters constant, the marginal benefit of effort is relatively higher in period 1 as it generates a reward for the two periods. As a consequence both players are incentivized to invest more effort in contests occurring in period 1 . This wealth effect is stronger the higher the discount factor.

Second, if the players' relative effort productivity changes over time, the effort invested tend to increase when the effort productivities converge. We say that the ratio of effort productivities converge if the ratio of effort productivities is closer to 1 in period 2 than in period 1 . Formally, we have convergence if $\max \left\{\frac{\theta_{i, 1}}{\theta_{j, 1}}, \frac{\theta_{j, 1}}{\theta_{i, 1}}\right\}>\max \left\{\frac{\theta_{i, 2}}{\theta_{j, 2}}, \frac{\theta_{j, 2}}{\theta_{i, 2}}\right\}$. In case of convergence, the ratio of total cost in period 1 over period 2 is smaller the higher the relative productivities in period 1 over period 2. Formally, if $\max \left\{\frac{\theta_{i, 1}}{\theta_{j, 1}}, \frac{\theta_{j, 1}}{\theta_{i, 1}}\right\}>\max \left\{\frac{\theta_{i, 2}}{\theta_{j, 2}}, \frac{\theta_{j, 2}}{\theta_{i, 2}}\right\}$, then:

$$
\frac{\partial\left(\frac{e_{i, 1}^{*}(C)+e_{j, 1}^{*}(C)}{e_{i, 2}^{*}(C)+e_{j, 2}^{*}(C)}\right)}{\partial\left(\frac{\theta_{i, 1} / \theta_{j, 1}}{\theta_{i, 2} / \theta_{j, 2}}\right)}<0
$$

The aggregate costs are thus greater if a contest occurs in period 1 than in period 2 in case of divergence. Otherwise, in case of convergence, the two forces go in opposite direction and the net effect depends on the extent to which the relative effort productivities converge over time.

To illustrate the results derived in this section, we have depicted in Figure 1 the equilibria of the game when player $j$ 's productivity of effort in period 1 is twice as high as the one of player $i$ $\left(\theta_{i, 1} / \theta_{j, 1}=1 / 2\right)$, and the players have a unit discount factor $(\delta=1)$. On the horizontal axis, one can read the ratio of effort productivities in period $2\left(\theta_{i, 2} / \theta_{j, 2}\right)$, and on the vertical axis we have represented the initial share of the resources allocated to player $i\left(\alpha_{i}\right)$. The areas abc and $a^{\prime \prime} b^{\prime \prime} c^{\prime \prime}$ describe the situations where a contest is unavoidable in period 2 as the ratio of player $i$ over player $j$ 's productivity in that period is significantly different than player $i$ 's share of the resources under a status quo $\left(\alpha_{i}\right)$. In the region $a b c$, player $i$ would initiate a contest with player $j$ in period 2 if a 
settlement is reached in period 1 , and conversely player $j$ would initiate a contest in period 2 in the region $a^{\prime \prime} b^{\prime \prime} c^{\prime \prime}$. In the region $a^{\prime} b^{\prime} c^{\prime}$, on the contrary, players would settle in period 2 . When player $i$ would initiate a contest in period $2($ area $a b c)$, three outcomes may emerge in period 1 . In zone a, player $j$ initiates a preventive contest. He would be better-off would a settlement be reached in the two periods but as he knows that player $i$ will initiate a contest in period 2, player $j$ is better off by precipitating it in period 1 . In the $b$ area, the two players settle in period 1 while they are both aware of player $i$ 's intention to initiate a contest in period 2. Lastly, in the $c$ zone player $i$ initiates a contest in period 1 as he has a small initial share of the resources and he expects a decline in the relative productivity of his effort in the future. Following the same reasoning, in the zones $a^{\prime}$ and $a^{\prime \prime}\left(c^{\prime}\right.$ and $\left.c^{\prime \prime}\right)$ player $j(i)$ initiates a contest in period 1 , while the players settle in $b^{\prime}$ and in $b^{\prime \prime} .^{7}$

[Figure 1 HERE] caption: Equilibrium outcomes for $\theta_{i, 1} / \theta_{j, 1}=0.5$ and $\delta=1$

\section{Balance of Power vs Power Transition Theory}

While economists have only lately been scrutinizing the inefficient allocation of resources to fighting activities, understanding the roots of peace and war has always been a major concern to political scientists. Two schools of thought propose seemingly contradicting theories in explaining which power configurations among rival nations are more likely to provoke armed conflict. According

\footnotetext{
${ }^{7}$ One could object that the players' efficiency parameters and their consequent win probabilities should reflect the players' initial allocation of property rights. This would amount to restricting the analysis to regions $a^{\prime}, b^{\prime}$, and $c^{\prime}$ on Figure 1. We purposefully decided not to constrain the problem in that direction, since interesting results arise in situations where the players' relative power does not reflect their relative property endowments.
} 
to the Balance of Power Theory (Morgenthau, 1960) war is less likely when the contenders are approximatively equally powerful, for the outcome of a clash is then the most uncertain. When the countries' power, however, fails to be balanced, the stronger elements will predate the weakest in order to further enhance their power. And although the Balance of Power Theory is certainly more complex and elaborate, the controversy between this theory and the Power Transition Theory (Organski, 1958; Organski and Kugler, 1980) is principally about the necessary conditions to have a peaceful world order. The Power Transition theory conceptualises a peaceful order as a hierarchical one, in a pyramidal distribution of power. The central claim of Power Transition theorists is that the occurrence of a conflict initiated by a dissatisfied rising challenger is more likely when $(i)$ the strength of the contestants is close, and when ( $i i)$ the rising state's power converges to the one of the dominant state. The literature has produced mixed evidence since both the balance of power theory (Moul 2003, Reed 2003, Toft 2007) and the power transition theory (Lebow and Valentino 2009) seem to have been falsified by econometric evidence. In light of our theory which reveals what we have termed the wealth effect and the convergence effect - dynamic strategic effects disregarded by existing IR theories and influencing the timing of conflict - both the Balance of Power Theory and the Power Transition Theory can be reconciled.

[Figure 2 HERE]

caption: Convergence of power and war

To illustrate the flexibility of our theory in explaining these two seemingly competing theories, assume that two countries $i$ and $j$ owning respectively shares $\alpha_{i}$ and $1-\alpha_{i}$ of some valuable resource (territory, natural resource,...) decide whether or not to engage in war today (time period $t$ ) and in the future $(t+1)$. On Figure 2 we represent an enlarged part of Figure 1 , for $\theta_{i, 1} / \theta_{j, 1}=1 / 2$, 
$\alpha_{i} \in[0 ; 0,3]$, and $\theta_{i, 2} / \theta_{j, 2} \in[0,4 ; 1]$. On this Figure we represent two different convergence scenarios. In the first one where $\alpha_{i}=0,2$, if no convergence occurs $(W)$ peace is secured over the two time periods. Indeed in that case the two countries' relative strength reflects their relative control of the resource, thus making peace preferable. Since there is no power convergence, or in other words since the balance of power is maintained, the countries have no incentives to wage war in $t+1$. As a consequence, in expectation of no power transition, both countries prefer maintaining peace today (i.e. in $t$ ) as well. If, however, the countries' relative military efficiency had shifted from 0,5 in $t$ to 0,75 in $t+1(X)$, the countries would expect an asymmetry in the future between the countries' relative strength and their relative territories. The balance of power would be disrupted in the future, and the rising state would accordingly go to war in $t+1$, thus corroborating the Balance of Power thesis. While the incentives to wage war today for the declining power are stronger than in the previous case (i.e. point $W$ ) because of country 2's expected conquests in the future, the peaceful option remains the preferred on in the short term for both countries. Hence, for so long as the balance of power is preserved, peace prevails, while when a country's power rises conflict occurs.

In the second scenario where country $i$ is twice poorer $\left(\alpha_{i}=0,1\right)$, the partition of the total territory would not reflect the countries' relative strength in the first time period. Should the countries not expect any power convergence $(Y)$, the disadvantaged country would have incentives to wage war immediately, so claim territories reflecting its might both today and in the future. On the other hand, if the relative military efficiency shifted from 0,5 in $t$ to 0,75 in $t+1(Z)$, the rising country's incentives to wage war in the future become very strong, eventually outmatching the incentives to wage war in the short run. As a consequence, the higher incentives to wage war in the future by the rising power could be interpreted as a validation of the Power Transition Theory. Had 
we considered other parameter configurations, our setting further allows to understand preventive wars (Levy 1987) in expectation of power transitions, hence bringing further support to the Power Transition Theory.

Our framework is therefore flexible enough to give credence to two central theories in International Relations, hence highlighting the need to further refine the mechanisms tying power shifts between nations to war.

\section{Conclusion}

In this paper we develop a model for the study of two-period contest games featuring two players. We derive two conditions for players to reach short run settled solutions despite the perspective of a future contest. These two conditions are that either players at least partially discount the future, or that the costs associated with the contest be lower in the future for both players. When contest effort is endogenous, the future cost reduction may result from two mechanisms. Following the first mechanism that we labeled the wealth effect, the players' incentives to expand costly effort in early contests is a positive function of the discounted amount of resources at stake in the contest. The wealth effect incentivizes players to delay contests. We also unveil another particular mechanism linked to the players' effort productivity shifting through time: if the players' relative contest productivity diverges through time, their aggregate contest effort is lower in future confrontations, thus further favoring short run settlements. On the other hand, if the players' relative contest productivity converges, the rising future contest-efforts incentivize players to opt for early contests. In the latter situation, whether delay occurs at equilibrium will be determined by the relative magnitude of the wealth and convergence effects.

We illustrate the usefulness of our framework by discussing two central theories in international 
relations: the Balance of Power Theory, and the Power Transition Theory. This model is shown to be flexible enough to accommodate both theories, thus demonstrating the need to further refine how the dynamic strategic considerations affect the mechanisms tying power shifts between nations to war. 


\section{References}

[1] Antonio E. Bernardo, Eric Talley, and Ivo Welch. A theory of legal presumptions. Journal of Law, Economics $\& 3$ Organization, 16 (1):1-49, 2000.

[2] Helmut Bester and Kai Konrad. Delay in contests. European Economic Review, 48:1169-1178, 2004.

[3] Helmut Bester and Kai Konrad. Easy targets and the timing of conflict. Journal of Theoretical Politics, 17 (2):199-215, 2005.

[4] Giacomo De Luca and Petros G. Sekeris. Deterrence in contests. Economica, 80 (317):171-189, 2012.

[5] Amy Farmer and Paul Pecorino. Legal expenditure as a rent-seeking game. Public Choice, 3-4:271-288, 1999.

[6] Michelle Garfinkel. Arming as a strategic investment in a cooperative equilibrium. American Economic Review, 80 (1):50-68, 1990.

[7] Michelle Garfinkel and Stergios Skaperdas. Conflict without misperceptions or incomplete information. Journal of Conflict Resolution, 44 (6):793-807, 2000.

[8] Jiong Gong and Preston R. Mcafee. Pretrial negociation, litigation, and procedural rules. Economic Inquiry, 38 (2):218-238, 2000.

[9] Herschel I Grossman and Minseong Kim. Sowrds or plowshares? a theory of the security of claims to property. The Journal of Political Economy, 103 (6):1275-1288, 1995.

[10] Jack Hirshleifer and Evan Osborne. Truth, effort, and the legal battle. Public Choice, 108 (1-2):169-195, 2001. 
[11] Avery Katz. Judicial decisionmaking and litigation expenditure. International Review of Law and Economics, 8(2):127-143, 1988.

[12] Kai Konrad. Strategy and Dynamics in Contests. Oxford University Press, 2009.

[13] Kai Konrad. Dynamic contests and the discouragement effect. Revue d'Economie Politique, 122:233-256, 2012.

[14] Richard Ned Lebow and Benjamin Valentino. Lost in transition: A critical analysis of power transition theory. International Interactions, 23(3):389-410, 2009.

[15] Jack Levy. Declining power and the preventive motivation for war. World Politics, 40(1):82$107,1987$.

[16] Michael McBride and Strergios Skaperdas. Institutions and Norms in Economic Development, chapter Explaining Conflict in Low-Income Countries: Incomplete Contracting in the Shadow of the Future, pages 141-161. Cambridge, MA: MIT Press, 2007.

[17] William Moul. Power parity, preponderance, and war between great powers, 1816-1989. Journal of Conflict Resolution, 47(4):468-489, 2003.

[18] A F K Organski. World Politics. Alfred A. Knopf, New York, 1958.

[19] A F K Organski and J Kugler. The War Ledger. The Chicago University Press, 1980.

[20] Robert Powell. Persistent fighting and shifting power. American Political Science Review, 56 (3):620-637, 2012.

[21] William Reed. Information, power, and war. American Political Science Review, 97(4):633-641, 2003. 
[22] Alex Robson and Stergios Skaperdas. Costly enforcement of property rights and the coase theorem. Economic Theory, 36:109-128, 2008.

[23] Stergios Skaperdas. Conflict and attitude toward risk. American Economic Review, 81 (2) Papers and Proceedings of the Hundred and Third Annual Meeting of the American Economic Association:116-120, 1991.

[24] Stergios Skaperdas. Bargaining versus fighting. Defence and Peace Economics, 17 (6):657-676, 2006.

[25] Stergios Skaperdas and Li Gan. Risk aversion in contests. Economic Journal, 105 (431):951962,1995 .

[26] Monica Toft. Power shifts and civil war: A test of power transition theory. International Interactions, 33(3):243-269, 2007.

[27] Gordon Tullock. Toward a Theory of the Rent-Seeking Society, chapter Efficient Rent Seeking, pages 97-112. Texas A\&M University Press, 1980. 


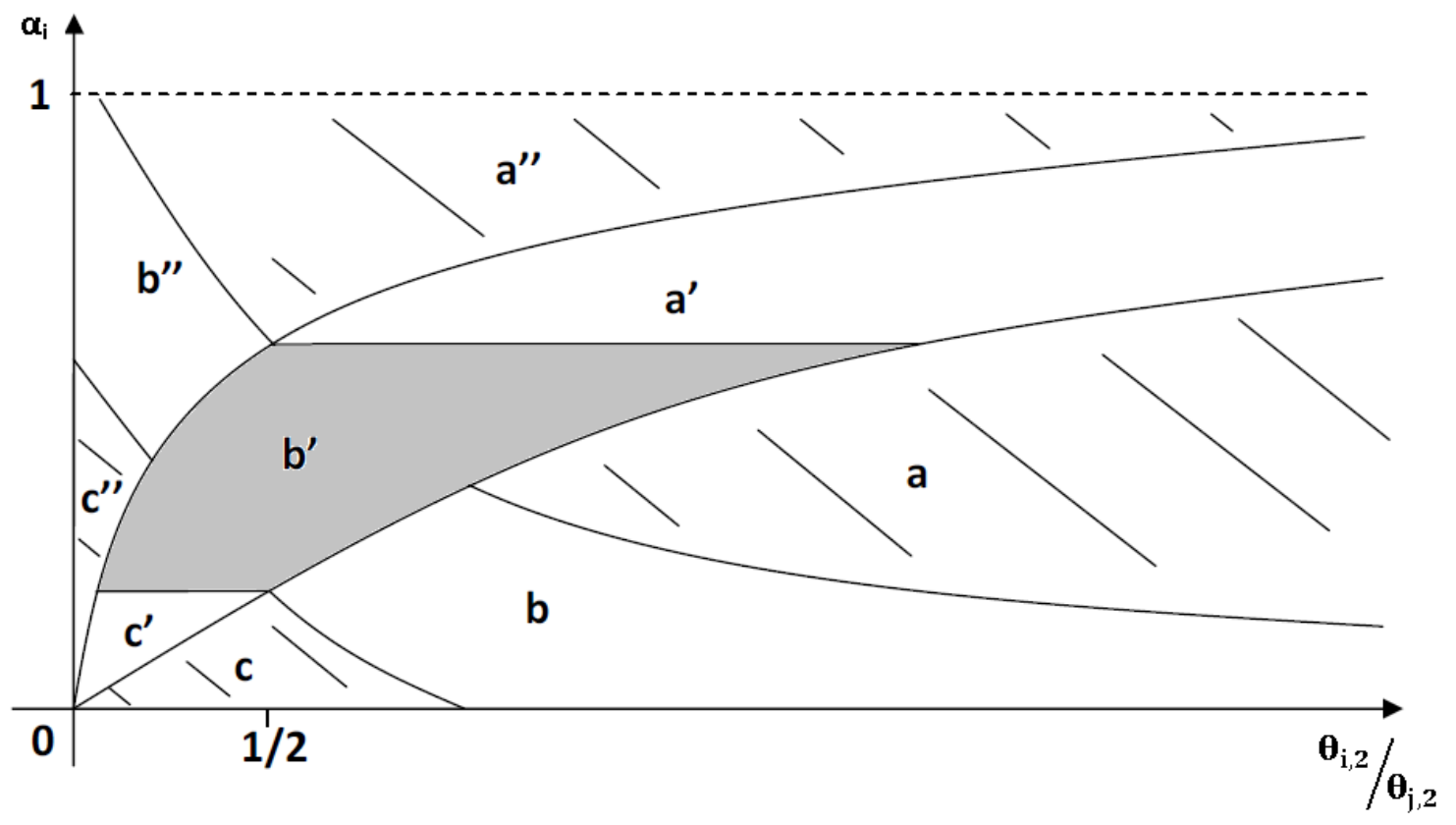

Figure 1: Equilibrium outcomes for $\theta_{i, 1} / \theta_{j, 1}=0.5$ and $\delta=1$ 


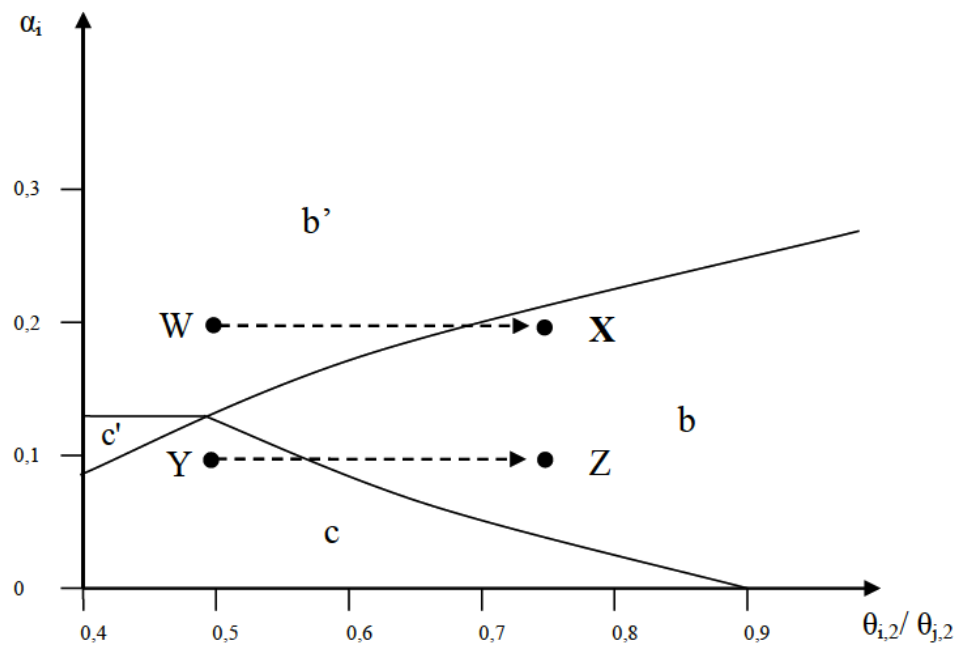

Figure 2: Convergence of power and war 